\title{
Moisture Regime with Respect to Spatial Variability of Soil Hydraulic Properties
}

\author{
Cs. FARKAS and K. RAJKAI \\ Research Institute for Soil Science and Agricultural Chemistry (RISSAC) of the \\ Hungarian Academy of Sciences, Budapest
}

In Hungary Mollisols, developed on loess parent material are the best for agricultural utilization. In agricultural practice they are handled and considered as homogeneous in most of the cases. Spatial variability of soil properties may appear in yield variation within a single field even in areas considered to be homogeneous from soil survey point of view. Our aim was to understand the relationship between the spatial pattern of soil hydraulic properties and that of soil moisture regime. We are convinced that it is important for soil management and crop production optimization purposes as well.

Effects of various sources of soil heterogeneity on the annual or long-term average soil water budget appear to differ markedly (KIM, 1995). As individual soil physical properties influence crop yield in different ways and in different magnitudes, we decided to integrate their influence by simulating the soil water balance and to use transpiration as a crop yield indicator. Simulation models are tools for analyzing the moisture regime with respect to physical properties of soils (MAJERCAK \& NOVAK, 1994; DJURHUUS et al., 1999). Simulation models, when used in field scale, have to be up-scaled from point validity soil profiles using geostatistical methods (VAN MEIRVENNE et al., 1995; TÓTH \& KUTI, 2002), or effective hydraulic parameters (SMITH \& DIEKKRÜGER, 1996). The use of effective hydraulic parameter values reduces the number of simulations significantly, but interprets the whole field as an equivalent soil profile. The disadvantage of this approach is that it does not reflect the spatial pattern of the soil water balance elements.

Our purpose was to analyze the differences of the soil water budget of a Mollisol due to spatial inhomogeneity of soil hydraulic properties (soil water retention characteristics (SWRC) and soil hydraulic conductivity function). We assumed that the field is composed of a set of one-dimensional non-interacting soil profiles and that each of them is represented by a set of soil hydraulic func-

Correspondence to: Csilla FARKAS, Research Institute for Soil Science and Agricultural Chemistry (RISSAC) of the Hungarian Academy of Sciences, H-1022 Budapest, Herman Ottó út 15. Hungary. E-mail: csilla@rissac.hu 
tions. The SWAP simulation model was applied for soil moisture regime simulations, and the scaling technique was used for spatial extension of the point model.

\section{Materials and Methods}

Experimental site. - The investigations were conducted on a Mollisol, formed on loam textured loess material at Herceghalom, Hungary $\left(47^{\circ} 30^{\prime} \mathrm{N}\right.$, $18^{\circ} 45^{\prime} \mathrm{E}$ ), representing one of the best and least variable Hungarian agricultural soils. The investigation area, belonging to the Herceghalom State Farm, was about $15 \mathrm{~km}^{2}$ (1500 ha), with a moderately undulating relief (130-200 $\mathrm{m}$ above the sea level).

The land use types in the study period were corn (498 ha), winter wheat (485 ha), alfalfa (150 ha) and grass (140 ha). The spatial variability of soil physical properties, caused probably by slight wind and water erosion as well as by differences in land use, was mainly expressed in the cultivated layer. Two representative soil profiles corresponding to the main land use types of corn and winter wheat were chosen. Description of the soil profiles was given by RAJKAI et al. (1997).

Sampling programme. - Disturbed and undisturbed $\left(100 \mathrm{~cm}^{3}\right)$ soil samples were taken from the genetic soil horizons of the representative soil profiles. Similar sampling was performed in the upper $(5-10 \mathrm{~cm})$ soil layer at $445 \mathrm{sam}-$ pling points. The allocation of the sampling points was defined using a geostatistical approach (RAJKAI \& KERTÉSZ, 1994; KERTÉSZ \& TÓTH, 1994).

Soil physical analyses. - The particle size distribution was determined from disturbed soil samples by the pipette method (BuZÁs, 1993). From the undisturbed cores, bulk density and soil water retention values were evaluated. The latter were measured at pressure heads (h) represented by $\mathrm{pF}$ values of $0.0,0.4$, $1.0,1.5,2.0,2.3,2.7,3.4$ and 4.2 according to VÁRALLYAY (1973). Soil water

Table 1

Means, standard deviations (SD) and coefficients of variation (CV) for soil bulk density $\left(\mathrm{g} / \mathrm{cm}^{3}\right)$, sand, silt and clay contents $(\%)$ and water contents $\left(\mathrm{m}^{3} / \mathrm{m}^{3}\right)$ at saturation $(\mathrm{pF}=0)$, field capacity $(\mathrm{pF}=2.3)$ and wilting point $(\mathrm{pF}=4.2)$

\begin{tabular}{|l|c|c|c|c|}
\hline \multicolumn{1}{|c|}{ Property } & $\mathrm{n}$ & Mean & SD & CV (\%) \\
\hline Bulk density & 445 & 1.33 & 0.10 & 7.5 \\
Sand & 445 & 11.48 & 3.12 & 27.1 \\
Silt & 445 & 61.98 & 6.43 & 10.3 \\
Clay & 445 & 26.18 & 4.57 & 17.4 \\
$\mathrm{pF}=0$ & 445 & 0.50 & 0.03 & 6.7 \\
$\mathrm{pF}=2.3$ & 445 & 0.36 & 0.03 & 7.7 \\
$\mathrm{pF}=4.2$ & 445 & 0.16 & 0.02 & 15.8 \\
\hline
\end{tabular}


retention data were expressed in terms of volumetric water content $(\Theta)$ using the bulk density of individual cores. The results of the statistical analyses of the 445 sampling point's data are given in Table 1.

Field measurements. - The near-saturated hydraulic conductivity $(\mathrm{K})$ of the soil surface (RAJKAI et al., 1993, 1997) was determined next to the representative profiles by a tension disc infiltrometer (ANKENY et al., 1988) at $-3,-6$ and $-12 \mathrm{~cm}$ tensions. The saturated hydraulic conductivity $\left(\mathrm{K}_{\mathrm{s}}\right)$ of the soil matrix was defined by the extrapolation of the exponential function, fitted to the measured conductivity values (ANKENY et al., 1988).

Volumetric soil water contents were measured in representative soil profiles up to $140 \mathrm{~cm}$ depth in $10 \mathrm{~cm}$ resolution, 7 (wheat) and 10 (corn) times in 1993 and 12 times during the vegetation period of 1994. The soil water content measurements were performed by capacitive probe developed at RISSAC (VÁRALLYAY \& RAJKAI, 1987).

Application of the SWAP simulation model. - The SWAP (Soil-WaterAtmosphere-Plant) simulation model (VAN DAM et al., 1997) was applied to estimate the elements of the soil water balance. The SWAP numerical model simulates the water flow in the unsaturated zone in relation to plant growth at field scale level for the entire growing season (VAN DAM, 2000). SWAP employs the Richards' equation for soil water movement in the soil matrix. The soil hydraulic functions, which relate $\Theta, \mathrm{h}$ and $\mathrm{K}$ are introduced by the analytical expressions of van Genuchten and Mualem (VAN GENUCHTEN, 1980). The model input data consisted of meteorological data, crop growth data, soil data plus initial and boundary conditions.

Daily meteorological data of the Martonvásár (located $20 \mathrm{~km}$ from Herceghalom) meteorological station, including air temperature, wind speed, solar radiation, air humidity for the vegetation periods of 1993-1994 were used to estimate the daily potential evapotranspiration according to Penman-Monteith (MONTEITH, 1981). SWAP calculates the potential and actual soil evaporations according to expressions suggested by BELMANS et al. (1983) and BOESTEN \& STROOSNIJDER (1986), respectively. The amount of daily precipitation was measured directly at the study area in 1993 and 1994.

The simple crop subroutine of the SWAP model was chosen, that requires data on crop height, leaf area index, root depth, root distribution and soil cover fraction as functions of the development stage. The crop parameters were set according to RAJKAI et al. (1997).

Initial conditions specified for the simulation consisted of initial soil water content profiles measured on Julian Day (JD): 130 and 151 in 1993 and 1994, respectively. Free flux bottom boundary conditions (no capillary water transport) were defined because of deep (below $5 \mathrm{~m}$ ) groundwater table.

The input data on soil properties, required by the model were the parameters of the soil water retention curve $\left(\Theta_{\mathrm{r}}, \Theta_{\mathrm{s}}, \alpha, \mathrm{n}\right.$ and $\left.\mathrm{m}=1-1 / \mathrm{n}\right)$ and hydraulic con- 
ductivity function $\left(\mathrm{K}_{\mathrm{s}}\right.$ and $\lambda$ ), specified for each genetic horizon of the soil profiles according to MUALEM (1976) and VAN GENUCHTEN (1980). The RETC computer program (VAN GENUCHTEN, 1980) was used to quantify the parameters of the Mualem-van Genuchten model based on the experimental data of soil water retention characteristics and measured values of saturated hydraulic conductivity. The input data are given in Table 2 .

\section{Table 2}

Fitted soil hydraulic function parameters: saturated $\left(\Theta_{\mathrm{s}}\right)$ and residual $\left(\Theta_{\mathrm{r}}\right)$ water contents, van Genuchten model parameters ( $\alpha$ and $n)$, saturated hydraulic conductivity $\left(\mathrm{K}_{\mathrm{s}}\right)$ and conductivity function parameter $(\lambda)$

\begin{tabular}{|c|c|c|c|c|c|c|c|}
\hline \multirow{5}{*}{ Wheat } & Layer $(\mathrm{cm})$ & $\begin{array}{c}\Theta_{\mathrm{r}} \\
\left(\mathrm{m}^{3} / \mathrm{m}^{3}\right)\end{array}$ & $\begin{array}{c}\Theta_{\mathrm{s}} \\
\left(\mathrm{m}^{3} / \mathrm{m}^{3}\right)\end{array}$ & $\begin{array}{c}\alpha \\
(1 / \mathrm{cm})\end{array}$ & $\begin{array}{c}\mathrm{n} \\
(-)\end{array}$ & $\begin{array}{c}\mathrm{K}_{\mathrm{s}} \\
(\mathrm{cm} / \mathrm{day})\end{array}$ & $\begin{array}{c}\lambda \\
(-)\end{array}$ \\
& $0-30$ & 0.06 & 0.47 & 0.012 & 1.25 & 10.1 & 0.15 \\
& $30-70$ & 0.06 & 0.51 & 0.052 & 1.22 & 8.6 & 0.14 \\
& $70-150$ & 0.01 & 0.49 & 0.021 & 1.26 & 8.6 & 0.21 \\
& $0-20$ & 0.09 & 0.49 & 0.012 & 1.26 & 15.2 & 0.17 \\
& $20-40$ & 0.01 & 0.46 & 0.014 & 1.16 & 10.5 & 0.18 \\
& $40-70$ & 0.01 & 0.50 & 0.040 & 1.14 & 10.5 & 0.18 \\
& $70-150$ & 0.01 & 0.47 & 0.023 & 1.25 & 8.6 & 0.22 \\
\hline
\end{tabular}

The SWAP model was calibrated for the representative soil profiles against the measured soil water content data. The climate-, location- and crop-specific parameters were set this way, so the sensitivity of the soil water regime characteristics to changes in soil physical properties could be studied further. Model adaptation was achieved by tuning of model parameters. Because of the uncertainties in the estimation of the hydraulic conductivity function parameters, these data were tuned during the calibration. The adaptation was continued until the precision of prediction stopped responding to the changes in model parameters. The method, suggested by ADDISCOTT (1993) was used to assess the accuracy of model fitting. Thus, the necessary level of accuracy (p) was defined and compared with the mean difference $(\mathrm{M})$ between the simulated $\left(\Theta_{\text {sim. }}\right)$ and measured $\left(\Theta_{\text {meas. }}\right)$ soil water content values:

$$
\mathrm{M}=\frac{1}{\mathrm{~N}} \sum_{\mathrm{i}=1}^{\mathrm{N}}\left|\Theta_{\text {meas }}-\Theta_{\text {sim }}\right|
$$

$\mathrm{N}$ refers for the number of cases. In case $\mathrm{M}<\mathrm{p}$, and the difference between the measured and simulated soil water contents does not exceed the accuracy level $\mathrm{p}$ in $85-90 \%$ of the cases, the adaptation of the model is successful. Taking into consideration the soil water content sampling and measurement errors the level of accuracy, $p$, was set as $\pm 5 \%$. 
The study consisted of four model calibrations (2 different years x 2 crops). In total 41 comparisons of measured and simulated soil water content profiles were performed: 7 (wheat) plus 10 (corn), and 12 (wheat) plus 12 (corn) for 1993 and 1994, respectively. The accuracy of the model fitting was tested for 11 layers in case of each profile. Hence, the M statistics was applied for 41x11 layers.

Spatial extension of the SWAP simulation model. - The scaling theory, introduced by MILLER \& MILLER (1956) was applied for the spatial extension of the simulation model results. The 445 soil water retention characteristic curves from the whole study area were scaled, using the SCALING software, developed by CLAUSNITZER et al. (1992). The program calculates a mean (reference) soil water retention curve for the study area and scaling factors for each SWRC curve, representing the deviation of the individual curve from the mean one. Providing the parameters of the reference curve and the scaling factors, SWAP generates the soil hydraulic functions for each scaling factor value and simulates the corresponding water balance. Thus, the elements of the soil water balance, such as transpiration, evaporation, leaching and changes in soil water storage were estimated for the 445 measurement points for the vegetation period.

The transpiration ratio $(\mathrm{R})$ between the simulated transpiration and potential transpiration values was calculated for each sampling point. In this respect we assumed uniform (wheat or corn only) vegetation cover in the whole area. Punctual kriging was applied as interpolation technique to demonstrate the spatial pattern of the simulated transpiration ratio. The spherical model was fit to the semivariogram.

\section{Results and Discussion}

The measured and calculated volumetric soil water content profiles for six days are presented in Figure 1. Figures show that predicted soil water content profiles do not differ much from the measured ones, so the simulation can be qualified as good. The difference between the two increases next to the soil surface and at the bottom of the profile, especially in case of wheat.

The model calibration for the uppermost layer is more difficult as compared to lower ones, because of the more complex nature of the water movement and redistribution phenomena (ZSEMBELI, 2000). On the other hand, the relative error of the capacitive probe, used for soil water content measurements, increases towards the soil surface. This might also be the reason of the less precise calibration of the model for the upper $15 \mathrm{~cm}$ layer. At the lower boundary a rather thick $(70-150 \mathrm{~cm})$ layer was considered to be homogeneous and represented by one set of soil hydraulic parameters. This assumption could cause inaccuracy in the simulated soil water content values of the $80-110 \mathrm{~cm}$ layers. 

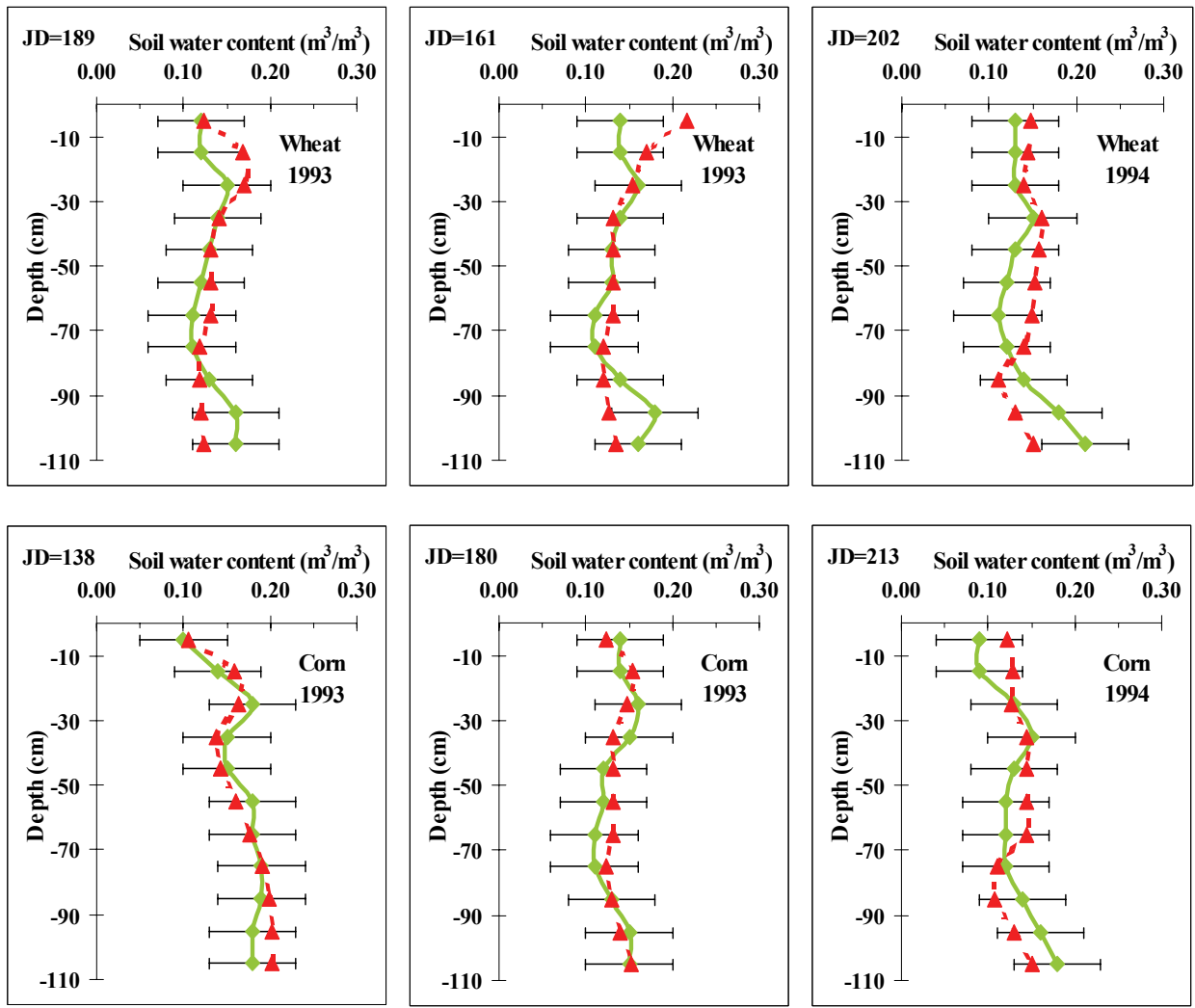

Figure 1

Measured $(\sigma$, dashed) and simulated $(\diamond)$ soil water content profiles (JD refers to Julian Days; the error bars are also indicated)

The model accuracy analyses according to ADDISCOTT (1993) are presented in Table 3. We concluded that the model calibration was successful in general. The differences between the simulated and observed soil water contents can be explained by seasonal changes in soil physical properties caused by biological

\section{Table 3}

The mean difference $(\mathrm{M})$ between the simulated and observed soil water content values and the percentage of cases $(\mathrm{K} \%)$ when the difference does not exceed the accuracy

$$
\text { level } \mathrm{p}=5 \%
$$

\begin{tabular}{|c|c|c|c|c|c|c|c|c|c|c|c|}
\hline \multicolumn{9}{|c|}{ Wheat } & \multicolumn{5}{c|}{ Corn } \\
\hline \multicolumn{3}{|c|}{1993} & \multicolumn{3}{|c|}{1994} & \multicolumn{3}{c|}{1993} & \multicolumn{3}{|c|}{1994} \\
\hline $\mathrm{M}$ & $\mathrm{K}$ & $\mathrm{N}$ & $\mathrm{M}$ & $\mathrm{K}$ & $\mathrm{N}$ & $\mathrm{M}$ & $\mathrm{K}$ & $\mathrm{N}$ & $\mathrm{M}$ & $\mathrm{K}$ & $\mathrm{N}$ \\
\hline 0.030 & 90 & 77 & 0.047 & 83 & 132 & 0.015 & 100 & 110 & 0.034 & 85 & 132 \\
\hline
\end{tabular}

$\mathrm{N}=$ number of cases 
activity and weather conditions. FARKAS et al. (1999) reported about strong seasonal variability of soil hydraulic properties of an agricultural soil and proved the sensitivity of the SWAP model to this variability (FARKAS et al., 2000). We suppose that taking into consideration the seasonal variability of soil physical properties might improve the simulation accuracy.

The spatial pattern of the simulated transpiration ratio for wheat is presented in Figures 2 and 3 for 1993 and 1994, respectively. The amount of precipitation differed greatly between the two years. 1993 was an extremely dry year with a total of $158 \mathrm{~mm}$ precipitation in the vegetation period. The following year was relatively wet with $302 \mathrm{~mm}$ of total rainfall during the growing season.

The spatial pattern of the simulated transpiration ratio for 1993 and 1994 was quite similar, but less uniform in the dry year. The transpiration range (not shown) was twice as big in 1993 (62 mm/growing season) than in 1994 (27 mm/growing season), the coefficients of variation were $6.8 \%$ and $1.8 \%$, respectively. The wider range and less uniform spatial pattern of the transpiration ratio in the dry year indicates that when conditions for crops are less favourable the effect of the spatial variability of soil hydraulic properties on the spatial pattern of the soil water balance is stronger.

Similar conclusions can be drawn regarding the spatial pattern of the simulated transpiration ratio for corn (not shown). The transpiration ranges for the vegetation period in this case were 59 and $22 \mathrm{~mm} /$ growing season, the coefficients of variation $5.3 \%$ and $1.5 \%$ in 1993 and 1994, respectively.

Note, that in this study neither the spatial pattern of the crop parameters nor the adaptation of the vegetation to unfavourable conditions were taken into account. No conclusions can be drawn for territories where no sampling points appear.

\section{Conclusions}

The adaptation of the SWAP simulation model to the Herceghalom study area was successful. We found that the spatial variability of the soil hydraulic properties influences the spatial pattern of the soil water balance elements, especially under dry, unfavourable conditions.

The applied method, namely the spatial extension of the SWAP simulation model, based on scaling of soil hydraulic properties is appropriate for optimization purposes and is suitable for precision agriculture aspects. It is possible to analyze the integrated effect of the variability of different soil physical properties on the soil water balance for a given crop and weather scenario. Moreover, this type of simulation allows the selection of the most appropriate land use pattern on the area.

Key words: water retention, scaling, spatial variability, modelling 


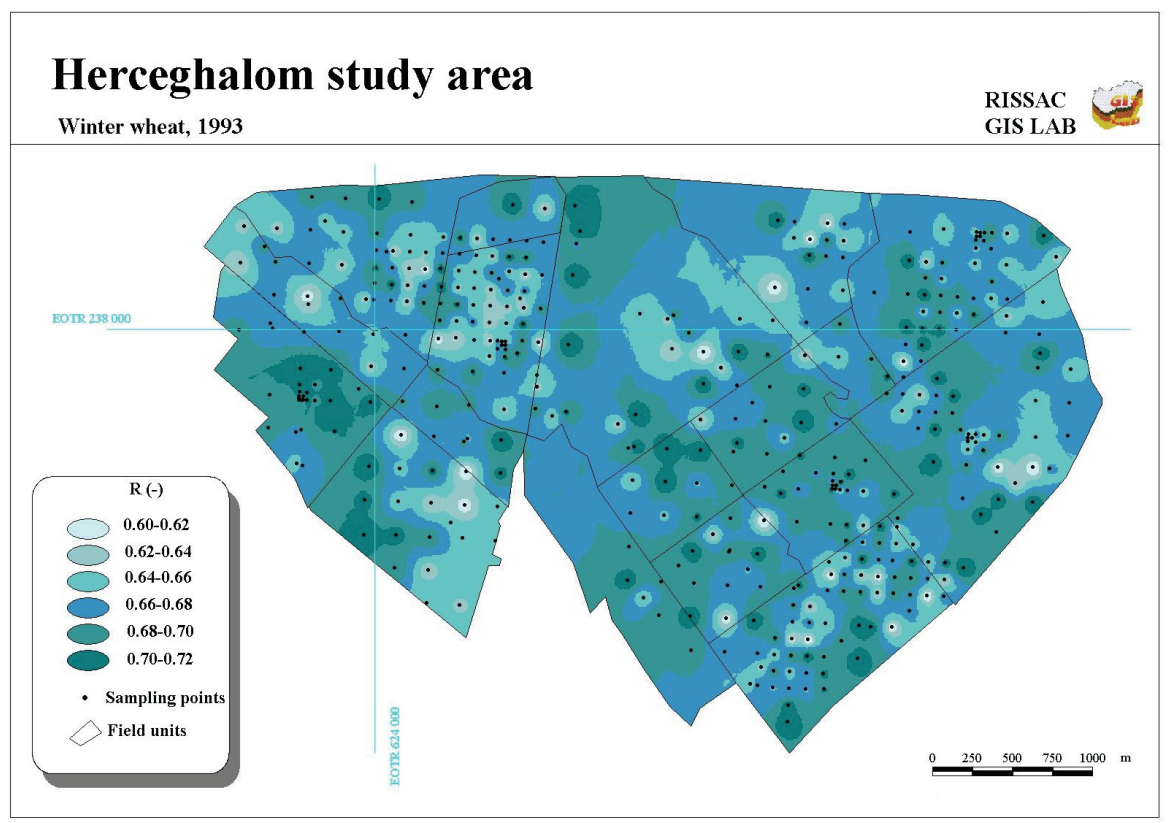

Figure 2

Spatial pattern of the simulated transpiration ratio R (-) for wheat (1993)

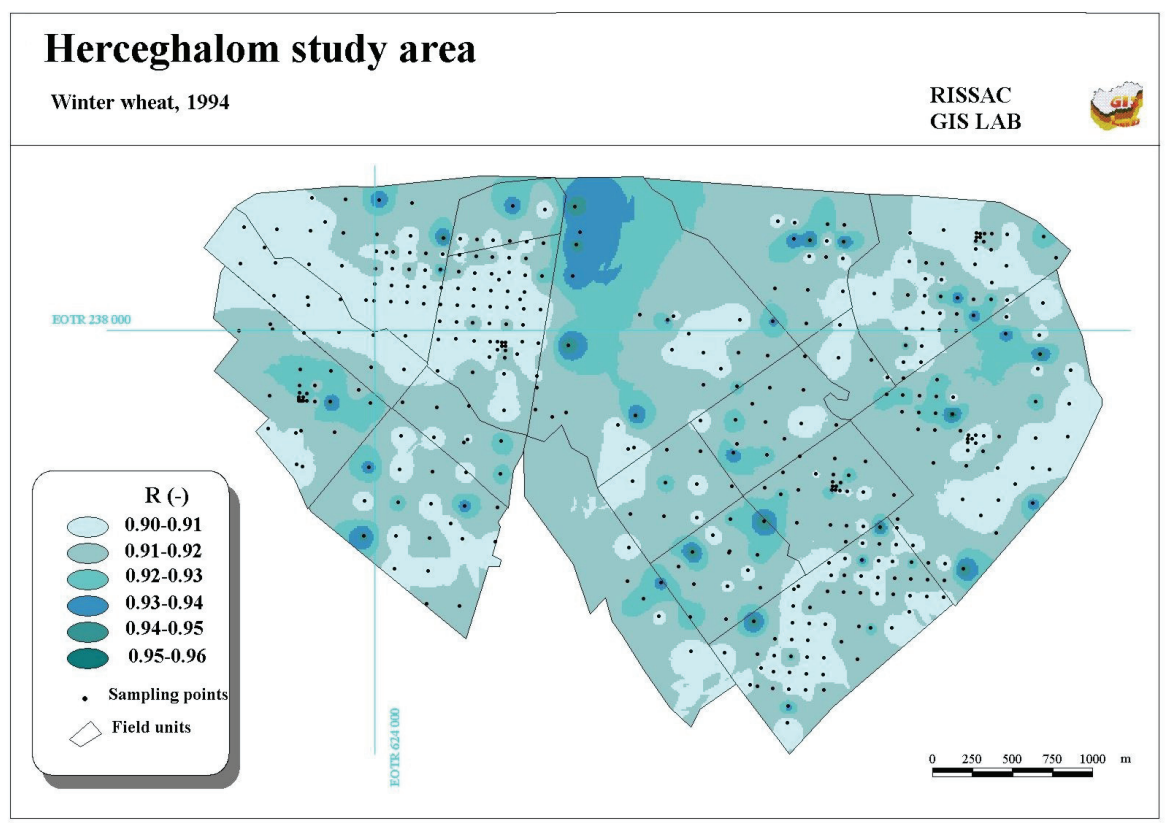

Figure 3

Spatial pattern of the simulated transpiration ratio R (-) for wheat (1994) 
This paper presents results of research programs supported by the National

Scientific Research Fund (OTKA, Grants No. F 015698 and 2530).

\section{References}

AdDiscotT, T., 1993. Simulation modelling and soil behaviour. Geoderma. 60. 15-40.

AnKenY, M. D., KaSPaR, T. C. \& HoRTON, R., 1988. Design for an automated tension infiltrometer. Soil Sci. Soc. Am. J. 52. 893-896.

Belmans, C., Wesseling, J. G. \& Feddes, R. A., 1983. Simulation of the water balance of a cropped soil: SWATRE. J. Hydrol. 63. 271-286.

Boesten, J. J. T. I. \& StroosniJder, L., 1986. Simple method for daily evaporation from fallow tilled soil under spring conditions in a temperate climate. Neth. J. Agric. Sci. 34. 75-90.

BuZÁs, I. (Ed.), 1993. Methods of Soil Analyses. Part 1. (In Hungarian) Mezőgazdasági Kiadó. Budapest.

Clausnitzer, V., Hopmans, J. W. \& Nielsen, D. R., 1992. Simultaneous scaling of soil water retention and hydraulic conductivity curves. Water Resour. Res. 28. 1931.

DJURHUUS, J. et al., 1999. Modelling mean nitrate leaching from spatially variable fields using effective hydraulic parameters. Geoderma. 87. 261-279.

FARKAS, Cs., GyuRicZA, Cs. \& LÁszló, P., 1999. Study on certain soil physical properties in long-term tillage experiments on brown forest soil in Gödöllö. (In Hungarian) Növénytermelés. 48. 323-336.

FARKAS, Cs. et al., 2000. Study of the influence of soil tillage on soil water regime. In: Subsoil Compaction. (Eds.: HoRn, R., VAN DEN AKKER, J. J: H. \& ARVIDSSON, J.) Advances in Geoecology. 32. 251-257. Catena Verlag. Reiskirchen, Germany.

KertéSZ, M. \& TótH, T., 1994. Soil survey based on sampling scheme adjusted to local heterogeneity. Agrokémia és Talajtan. 43. 113-132.

KiM, R., 1995. The water budget of heterogeneous areas. Doctoral thesis. Wageningen Agricultural University. Wageningen, The Netherlands.

MAJERČ́́K, J. \& NOVÁK, V., 1994. One-dimensional variably saturated flow model GLOBAL, Version 2.1. Institute of Hydrology, Slovak Academy of Sciences. Bratislava, Slovak Republic.

MilleR, E. E. \& MilleR, R. D., 1956. Physical theory for capillary flow phenomena. J. Appl. Phys. 27. 324-332.

MonTEITH, J. L., 1981. Evaporation and surface temperature. Quarterly J. Royal Soc. 107. 1-27.

MUALEM, Y., 1976. A new model for predicting the hydraulic conductivity of unsaturated porous media. Water Resour. Res. 12. 513-522.

RAJKAI, K. \& KERTÉSZ, M., 1994. Spatial estimation and quantitative mapping of the soil water capacity and transport. Report of the HNRF project No. 2530. (In Hungarian) RISSAC. Budapest.

RAJKAI, K. et al., 1993. Use of tension infiltrometer and water retention characteristics in the assessment of soil structure. International Agrophysics. 7. 141-154.

RAJKAI, K. et al., 1997. Impacts of soil structure on crop growth. International Agrophysics. 11. 97-109. 
SMITH, R. E. \& DIEKKRÜGER, B., 1996. Effective soil water characteristics and ensemble soil water profiles in heterogeneous soils. J. Geophys. Res. 32. 1993-2002.

TÓTH, T. \& KUTI, L., 2002. Testing alternative tecniques of numerical simulation versus repeated field instrumental measurements for assessing soil salinity status in a sodic grassland. Agrokémia és Talajtan. 51. 243-252.

VAN DAM, J., 2000. Field-scale water flow and solute transport. Ph.D. thesis. Wageningen Agricultural University. Wageningen, The Netherlands.

VAN DAM, J. C. et al., 1997. Simulation of water flow, solute transport and plant growth in the Soil-Water-Atmosphere-Plant environment. Wageningen Agricultural University. Wageningen, The Netherlands.

VAN GENUCHTEN, M. TH., 1980. A closed-form equation for predicting the hydraulic conductivity of unsaturated soil. Soil Sci. Soc. Am. J. 44. 892-898.

VAN MEIRVENNE, M. et al., 1995. Spatial extension of a point water balance model. In: Scenario Studies for the Rural Environment. (Eds.: SCHOUTE, J. F. TH. et al.) 293297. Kluwer. The Netherlands.

VÁRALlYAY, GY., 1973. A new apparatus for the determination of soil moisture potential in the low suction range. (In Hungarian) Agrokémia és Talajtan. 22. 1-22.

VÁRAllyAY, GY. \& RAJKAI, K., 1987. Soil moisture content and moisture potential measuring techniques in Hungarian soil survey. In: Proc. Intern. Conf. on "Measurement of Soil and Plant Water Status", July 6-10, 1987. 1. 183-184. Logan, Utah, USA.

ZSEMBELI, J., 2000. Effect of soil surface types on the moisture regime of different soil layers. In: Proc. $2^{\text {nd }}$ Workshop and Intern. Conference on Subsoil Compaction, Gödöllö. 204-208. 